\title{
AVALIAÇÃO DOS REGISTROS DE INCÊNDIOS FLORESTAIS DO ESTADO DO PARANÁ NO PERÍODO DE 1991 A 2001
}

\author{
Jackson Luiz Vosgerau*, Antonio Carlos Batista**, Ronaldo Viana Soares***, Leocádio Grodzki**** \\ *Eng. Florestal, M.Sc. - vosgerau@floresta.ufpr.br \\ **Eng. Florestal, Dr., Depto. de Ciências Florestais, UFPR - batista@floresta.ufpr.br \\ ***Eng. Florestal, Ph.D., Depto. de Ciências Florestais, UFPR - rvsoares@ufpr.br \\ ****Eng. Agrônomo, Dr., SIMEPAR - lgrodzki@ufpr.br \\ Recebido para publicação: 25/10/2005 - Aceito para publicação: 21/03/2006
}

\begin{abstract}
Resumo
Este trabalho foi realizado objetivando a avaliação dos registros de incêndios ocorridos no estado do Paraná no período de 1991 a 2001, visando disponibilizar informações sobre o número total de incêndios ocorridos, os meses do ano de maior incidência, as formas vegetacionais e as regiões do Estado mais atingidas. Foram pesquisados 220.000 documentos para compilação final dos dados referentes a combate ou registro com fogo pertencentes ao Grupamento do Corpo de Bombeiros (GB) do Estado do Paraná, que resultaram em 15.890 registros de incêndios ou queimadas em vegetações. Os resultados obtidos através deste estudo permitiram concluir que: a) os anos de 1994, 1999 e 2000 apresentaram ocorrências de incêndios acima da média; b) a maior incidência de incêndios florestais no Paraná aconteceu nos meses de julho, agosto e setembro; c) o maior número de ocorrências de incêndios registrados foi na região Norte do estado do Paraná; d) o município de Londrina apresentou o maior número de registros de incêndios atendidos pelo Corpo de Bombeiros; e) os tipos de vegetação mais atingidos pelos incêndios no período foram as matas e vegetação rasteira característica de campos nativos.

Palavras-chave: Incêndios florestais; estatísticas; registros de ocorrência.
\end{abstract}

\begin{abstract}
Evaluation of forest fire registers of the State of Parana in the period from 1991 to 2001. This research was conducted with the objective of an evaluation of the fire report occurred in the state of Paraná in the period between 1991 and 2001, aiming to show information about the total number of fires occurred, the months of highest occurrence, the vegetation types and the regions of the state that where most affected. 220000 documents where studied to the final compilation of data referring to fire reports from the registers of the fireman of Paraná, which resulted in 15890 reports of forest fires. The results of this study allowed us to conclude that: a) in 1994, 1999 and 2000 the number of fire occurrences was above the average; b) the higher incidence of forest fires in Paraná happened in the months of July, August and September; c) the higher number of fires was registered in the north of the state of Paraná; d) Londrina presented the higher number of reports of fires attended by the Fireman Corporation and; e) the vegetation of small size of native forests were the most affect ones. Keywords: Forest fire; statistics; registers of occurrences.
\end{abstract}

\section{INTRODUÇÃO}

Os incêndios florestais são causadores diretos de prejuízos econômicos e sociais cujas dimensões muitas vezes atingem níveis incalculáveis. O estado do Paraná, bem como o restante do País, carece de planos de prevenção e controle efetivos. Planos estes que só podem ser organizados e colocados em prática mediante a avaliação de informações que relatem precisamente as características das ocorrências dos incêndios.

Para o desenvolvimento dos planos de prevenção, é preciso, segundo Soares (1985), conhecer o perfil dos incêndios florestais, isto é, saber onde, quando e por que ocorreram os incêndios. São essas informações que geram as estatísticas que constituem a base fundamental para esse tipo de estudo. A falta de informações sobre os incêndios florestais pode levar a extremos: por um lado, gastos elevados em 
prevenção por desconhecimento do potencial de danos; por outro lado, investimentos muito pequenos, colocando em risco a sobrevivência da floresta (VOSGERAU, 2005).

Os dados mais freqüentes usados como guias para os programas de prevenção são as causas dos incêndios, a época, o lugar de ocorrência e a extensão da área queimada. É importante saber onde ocorrem os incêndios para definir as regiões de maior risco e, conseqüentemente, estabelecer prioridades através de programas mais intensivos de prevenção e controle de incêndios. A distribuição dos incêndios através dos meses do ano é outra informação importante no planejamento da prevenção, pois permite conhecer as épocas de maior risco de ocorrências. A extensão da área queimada nos incêndios é útil para analisar a eficiência do combate. Quanto melhor a eficiência da equipe de combate, menor é a extensão da área queimada (BATISTA; SOARES, 1997).

Diante desse contexto, percebe-se a importância da coleta de dados de forma padronizada, no sentido de fornecer informações confiáveis que possam ser utilizadas para gerar estatísticas, propiciando bases concretas para disponibilização de recursos, tanto financeiros quanto humanos, além de investimentos adequados na área de proteção florestal.

Este trabalho objetiva a avaliação dos registros de incêndio ocorridos no estado do Paraná no período de 1991 a 2001, visando disponibilizar informações sobre o número total de incêndios ocorridos, os meses do ano de maior incidência, as formas vegetacionais e as regiões do Estado mais atingidas.

\section{MATERIAL E MÉTODOS}

\section{Caracterização da área de estudo}

O Paraná está localizado na região Sul do Brasil, entre os paralelos $22^{\circ} 30^{\prime} 58^{\prime \prime}$ de latitude Norte e

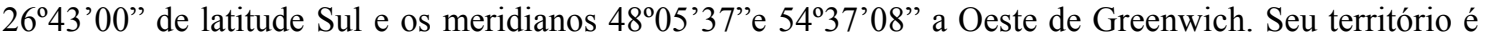
composto de uma área de $199.314,850 \mathrm{~km}^{2}$, correspondente a 2,4\% da área do Brasil e 35\% da área da região Sul. O Paraná, em 2000, era constituído por 399 municípios. A população residente era de 9.558.458 habitantes, com densidade demográfica média de 47,99 hab/ $\mathrm{km}^{2}$, sendo que 7.781 .664 habitantes residiam na área urbana e 1.776.794 habitantes na área rural. No Paraná, as altitudes variam desde o nível do mar até 1.922 metros no Pico do Paraná, localizado na Serra do Mar, ponto mais elevado do Estado e da região Sul. Aproximadamente $80 \%$ da área total encontra-se entre 200 e 800 metros acima do nível do mar (IBGE, 2004).

A superfície do estado do Paraná caracteriza-se por uma diversidade fitogeográfica notável, onde diferentes tipos de florestas ocorrem entremeadas por formações herbáceas e arbustivas, resultantes de peculiaridades geomorfológicas, pedológicas e climáticas. Restam atualmente menos de $9 \%$ da situação original em bom estado de conservação, percentagem que inclui cerca de $2 \%$ de vegetação restaurada em áreas protegidas. Originalmente, $83 \%$ de sua superfície eram áreas cobertas por florestas. As 17\% restantes eram ocupadas por formações não-florestais (campos e cerrados), completadas por vegetação pioneira de influência marinha (restingas), flúvio-marinha (mangues) e flúvio-lacustre (várzeas), e pela vegetação herbácea do alto das montanhas - campos de altitude e vegetação rupestre (RODERJAN et al., 2002).

Na porção Leste do Estado, com altitude máxima de 1.887 m, situa-se a região da Floresta Ombrófila Densa (Floresta Atlântica). Estão incluídas, nesse caso, as formações florestais da Planície Litorânea, das encostas da Serra do Mar e da parte do Vale da Ribeira. A oeste dessa serra, ocupando as porções planálticas do Estado ( 800 a $1200 \mathrm{~m}$ de altitude), situa-se a região da Floresta Ombrófila Mista (floresta com araucária), sem influência direta do oceano. A composição florística é fortemente influenciada pelas baixas temperaturas e pela ocorrência de geadas de inverno (RODERJAN et al., 2002).

\section{Metodologia}

Os dados da pesquisa foram obtidos das informações coletadas, registradas e armazenadas pelo Grupamento do Corpo de Bombeiros (GB) do estado do Paraná, que encontravam-se arquivadas nas unidades descentralizadas dos seguintes comandos: $1^{\circ}$ GB Curitiba, $2^{\circ}$ GB Ponta Grossa, $3^{\circ}$ GB Londrina, $4^{\circ}$ GB Cascavel, $5^{\circ}$ GB Maringá, $6^{\circ}$ GB São José dos Pinhais, $1^{\circ}$ SGBI Foz do Iguaçu, $2^{\circ}$ SGBI Paranaguá, denominados de COREDEC - Coordenação Regional de Defesa Civil (Figura 1). Os dados registrados eram baseados em perguntas de formulário pré-elaborado, para respostas descritivas, objetivas ou mesmo mistas, sendo que esses formulários eram de aplicação geral aos atendimentos do Corpo de 
Bombeiros, consistindo de todo tipo de ocorrência, como atendimento de acidente automobilístico, vítima de trânsito, ocorrências com animais e incêndios diversos.

No laboratório de incêndios florestais da Universidade Federal do Paraná, foram pesquisados 220.000 documentos para compilação final dos dados referentes a combate ou registro com fogo. Inicialmente foram manuseados 120 livros tipo "ATA", que formavam os arquivos até o início do ano de 1993. Posteriormente, foram analisados os documentos que consistiam de formulários pré-elaborados e mimeografados em forma de questionários e que se encontravam armazenados em caixas de arquivos do tipo papelão, com aproximadamente 1000 documentos por caixa, perfazendo um montante de 220 caixas. Dos 220.000 documentos, aproximadamente 17.000 eram registros de incêndios. Destes, somente 15.890 eram exclusivos de incêndios ou queimadas em vegetações.

Os registros que continham ocorrências de incêndios ou queimadas envolvendo algum tipo de vegetação foram registrados em formulários previamente elaborados, de maneira a estabelecer um banco de dados em software Excell que permitisse a análise dessas informações.

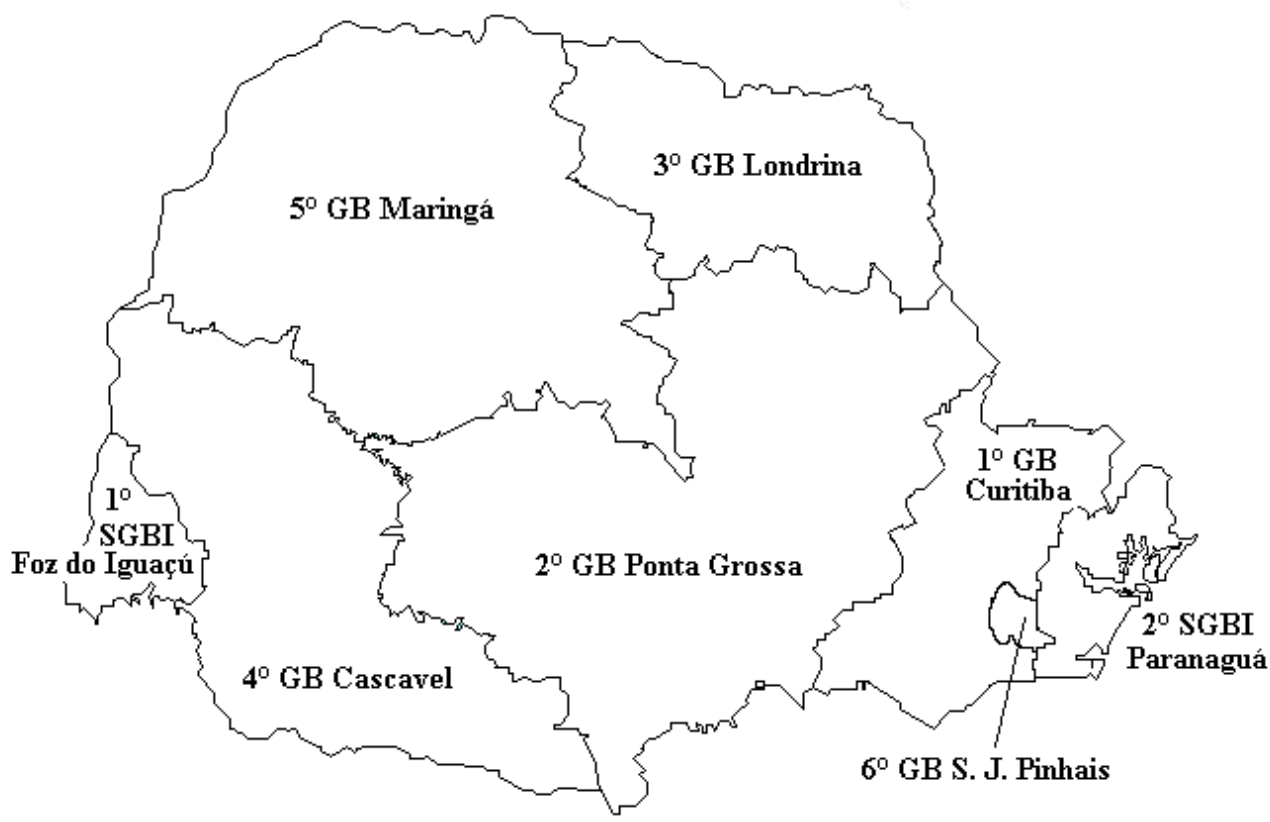

Figura 1. Distribuição dos 8 grupamentos de bombeiros do estado do Paraná.

Figure 1. Distribution of the 8 groupings of firemen of Paraná State.

FONTE: Núcleo de Informática Casa Militar - Defesa Civil (2002).

\section{Análise dos dados}

Os dados do período de 1991 a 2001 foram analisados por ano, por mês, por regiões e também considerando a região da divisão administrativa de cada grupamento ou corporação do Corpo de Bombeiros.

Foram analisadas as seguintes informações:

a) número total de incêndios ocorridos no período;

b) principais regiões atingidas no Estado;

c) a época de ocorrência;

d) os dias e horários mais freqüentes das ocorrências;

e) a área total queimada por município;

f) as causas dos incêndios;

g) o tipo de vegetação atingida.

Quanto ao tipo de vegetação atingida pelos incêndios florestais, foram encontrados nos relatórios do Corpo de Bombeiros 86 tipos de combinações de formações vegetais descritas de forma diferente. 
Estas foram reclassificadas ou interpretadas como sendo apenas 6 diferentes tipos ou nomenclaturas (Tabela 1), a saber:
a) limpeza para agricultura: todas as atividades relacionadas ao plantio agrícola;
b) vegetação rasteira: pastos e campos;
c) capoeira;
d) mata: florestas nativas;
e) reflorestamento;
f) sem classificação específica: a tipologia vegetal atingida não foi classificada.

Tabela 1. Número de registros de ocorrências de incêndios em relação à tipologia vegetal afetada.

Table 1. Number of fire occurrences in relation to the affected vegetal types.

\begin{tabular}{lcc}
\hline Tipo de vegetação & Número de ocorrências & \% \\
\hline Resíduos de agricultura & 532 & 3,3 \\
Vegetação rasteira & 4.818 & 30,3 \\
Capoeira & 3.934 & 24,8 \\
Mata & 4.944 & 31,1 \\
Reflorestamento & 547 & 3,4 \\
Sem classificação específica & 1.115 & 7,1 \\
\hline Total & 15.890 & 100,0 \\
\hline
\end{tabular}

\section{RESULTADOS E DISCUSSÃO}

\section{Total de ocorrências}

No período de 1991 a 2001 foram registrados 15.890 incêndios, representando uma média anual de 1.444,5 ocorrências distribuídas conforme a figura 1.

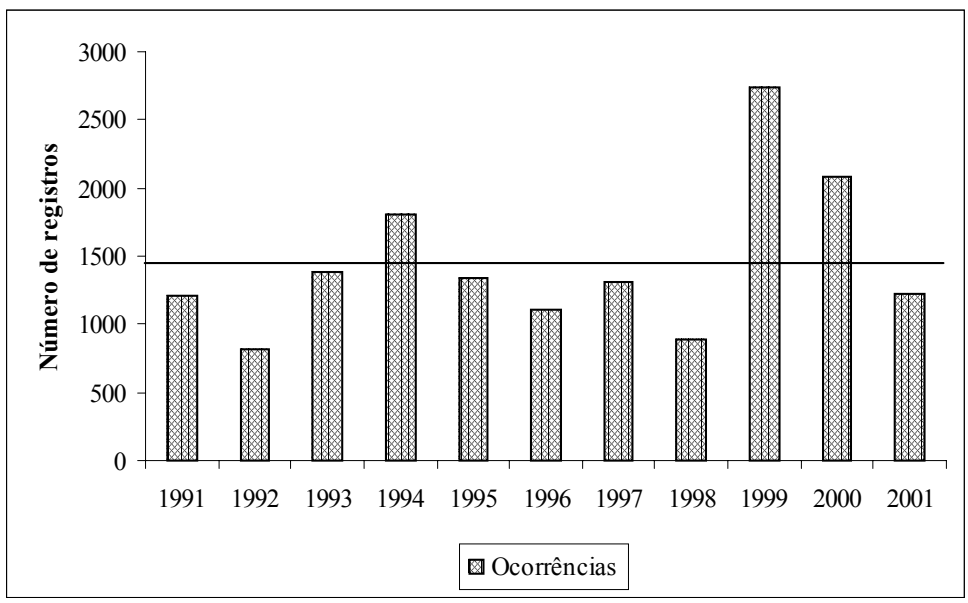

Figura 1. Número de ocorrências de incêndios florestais no período de 1991 a 2001.

Figure 1. Number of forest fire occurrences in the period of 1991 to 2001.

Analisando-se as ocorrências anuais, pôde-se observar que foram três os anos (1994, 1999 e 2000) em que as ocorrências estiveram acima da média anual registrada.

Mediante os 11 anos de registros de incêndios, optou-se pela avaliação das médias trienais destes, com o objetivo de demonstrar a tendência das ocorrências dos incêndios durante esse período (Figura 2). Com isso, verificou-se um aumento da ordem de 176,86 \% entre o primeiro e o quinto triênios - respectivamente os anos de 1991 a 1993 e 1999 a 2001 - cuja média das ocorrências saltou de 1.138 para 2.012,7 registros.

A partir do conhecimento do perfil dos incêndios florestais, é possível planejar e investir adequadamente nas campanhas de prevenção, como uma das formas de conter o crescimento dos 
incêndios no Estado. Além disso, essa informação permite que as equipes de combate sejam corretamente equipadas e treinadas.

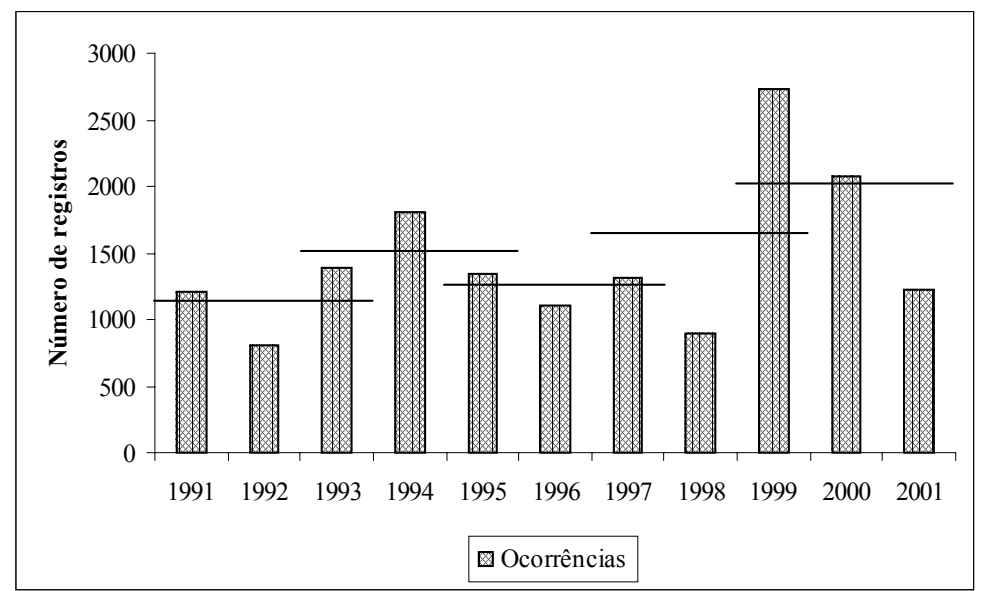

Figura 2. Médias trienais das ocorrências de incêndios no período de 1991 a 2001.

Figure 2. Triennial averages of the fire occurrences in the period of 1991 to 2001.

De acordo com os dados obtidos, o ano de 1999 foi o responsável pelo maior número de registros de incêndios, seguido pelo ano de 2000. Juntos, eles foram responsáveis por 30,27\% das ocorrências registradas.

A figura 3 apresenta as ocorrências de incêndios distribuídas através dos meses do ano durante o período estudado.

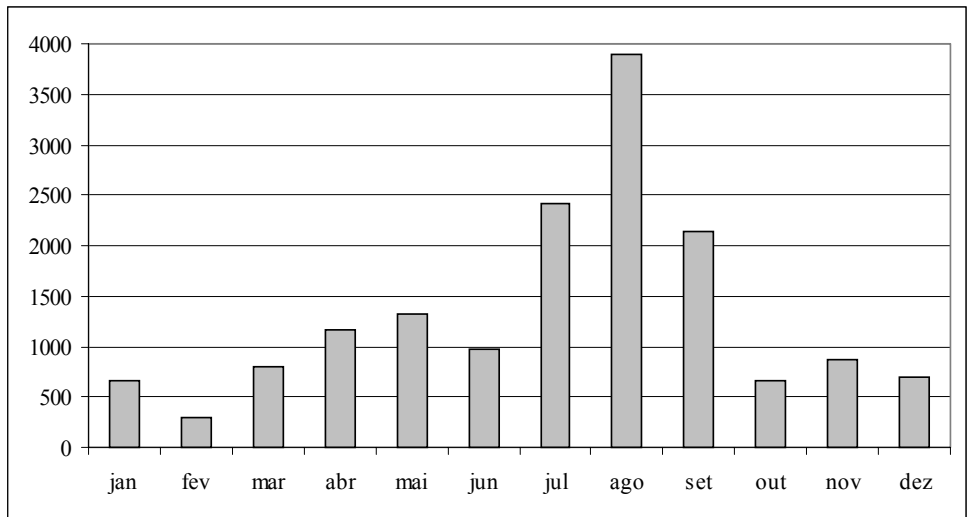

Figura 3. Médias dos números de ocorrências de incêndios florestais registrados por mês no período de 1991 a 2001.

Figure 3. Averages of the numbers of forest fire occurrences registered by month in the period of 1991 to 2001.

As informações da figura 3 coincidem com os estudos realizados por Soares (1985), que, com base nos dados obtidos em áreas restritas no estado do Paraná, comprovaram a maior incidência das ocorrências de incêndios para os meses de julho, agosto e setembro, período de final de inverno e início da primavera, época da limpeza e preparo dos solos para o plantio agrícola.

Segundo Soares e Santos (2002), as ocorrências de incêndio no Paraná e no Brasil estendem-se de julho a setembro, resultados idênticos aos observados no período de 1983 a 1987 (SOARES, 1989), mostrando que, efetivamente, o problema dos incêndios florestais no Brasil se concentra no inverno e início de primavera. 
Considerando o custo envolvido no preparo dos solos agrícolas, o sistema que demanda menor investimento é o uso do fogo, que continua sendo uma prática comum neste Estado e concentrando-se sempre no mesmo período do ano. As informações registradas demonstram objetivamente que esse trimestre específico é mais crítico para ocorrência dos incêndios florestais por apresentar as médias mais baixas de índices de precipitação e de umidade relativa do ar, o que contribuiu significativamente para o aumento da estatística de ocorrências dos incêndios no Estado.

Conforme a figura 3 , agosto é o mês com o maior número de ocorrências $(24,47 \%)$, e, se classificado por trimestre, também os meses de julho, agosto e setembro registram a maior incidência: $53,18 \%$ de todos os incêndios registrados no período.

\section{Distribuição das ocorrências de incêndios no estado do Paraná}

A figura 4 apresenta a distribuição da ocorrência do número de incêndios por Unidade de Comando do Corpo de Bombeiros do Paraná. Nele observa-se que o $3^{\circ}$ GB Londrina apresentou o maior número de atendimentos, com 25,85\%, seguido de Maringá (18,44\%) e Ponta Grossa (17,54\%).

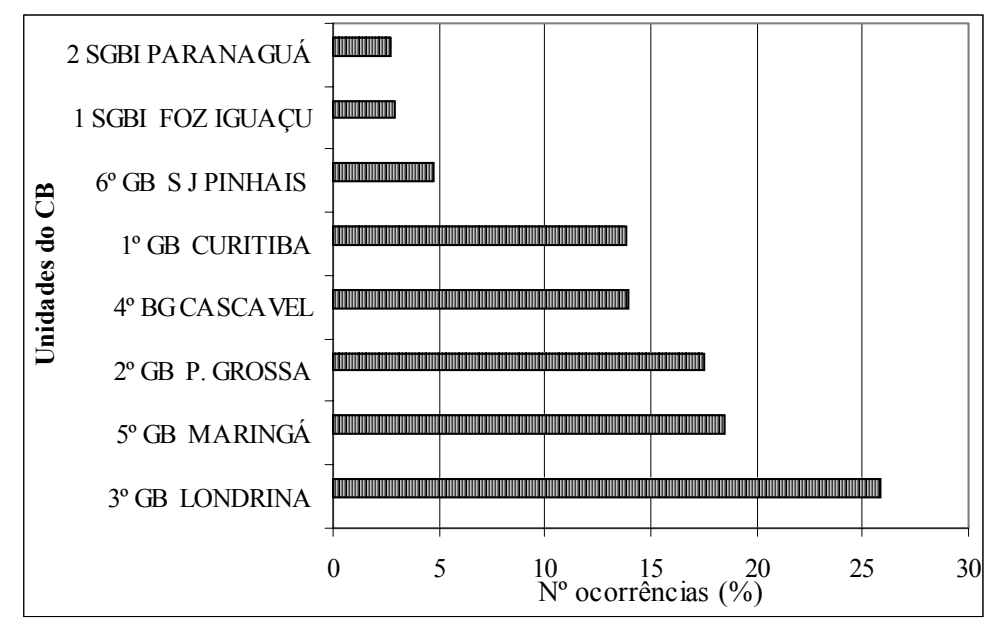

Figura 4. Distribuição total das ocorrências de incêndios florestais por unidade de comando do corpo de bombeiros do estado do Paraná no período de 1991 - 2001.

Figure 4. Total distribution of the forest fire occurrences for unit of command of fire department of Paraná State in the period of $1991-2001$.

O clima, caracterizado por temperaturas elevadas e baixa umidade relativa do ar, contribui para o maior número de ocorrências de incêndios atendidas pelo $3^{\circ} \mathrm{GB}$ de Londrina. Outro provável fator devese ao fato de a região ser uma das mais produtivas do Estado, de maneira que suas áreas encontram-se continuamente em produção e dificilmente passam por um período de repouso para sua recuperação. $\mathrm{O}$ uso do fogo para a limpeza do solo ocorre de forma contínua, e os riscos da utilização dessa prática expressam-se claramente nos registros de incêndios, pois o fogo, ao sair do controle, geralmente se estende aos capoeirões, às matas degradadas e também às pequenas áreas abandonadas em regeneração.

O $5^{\circ}$ GB Maringá enfrenta problemas semelhantes aos da região de Londrina. As principais ocorrências se iniciam com a queima de vegetação rasteira, seguidas da queima de vegetação arbustiva em pequenas áreas abandonadas e por queima de resíduos da safra agrícola em áreas rurais. Considerando que o clima de parte da região é um dos mais quentes do estado, que a umidade relativa do ar está entre as mais baixas e que a vegetação rasteira nas pequenas propriedades é controlada com uso do fogo, ocorrem incêndios como conseqüência da época de preparo dos solos. Faz-se necessário mencionar que as regiões de Londrina e Maringá apresentam ainda o agravante de possuírem uma grande densidade populacional.

A região do $2^{\circ}$ GB Ponta Grossa é a maior em cobertura de área do Estado para ser atendida por um único grupamento. Essa região se caracteriza por concentrar grandes áreas de campos nativos e de produção florestal do Estado. Também existe uma significativa área de remanescente florestal nativo, com grande ocorrência da Araucaria angustifolia (Bert.) O. Ktze. Os incêndios foram caracterizados nos 
registros principalmente como incêndio de vegetação rasteira ou, nesse caso, queima de campos nativos para renovação de pasto ou mesmo para manutenção do campo limpo. Também registraram-se incêndios em pequenas áreas abandonadas.

Na região do $4^{\circ} \mathrm{GB}$ Cascavel, a característica dos incêndios foi similar à da região de Maringá, ocorrendo em áreas de vegetação rasteira e pequenas áreas abandonadas.

Na região do $1^{\circ}$ GB Curitiba, o maior número de incêndios atendidos teve início nas áreas de vegetação rasteira, seguido das áreas de floresta nativa, onde a vegetação típica são os campos limpos com florestas de Araucaria angustifolia, e também das queimas em áreas de bracatinga manejada, que têm como característica o uso do fogo para renovação de sua produção.

\section{Ocorrências por município}

Foram registradas ocorrências de incêndios florestais em 97 municípios de um total de 399, tendo sido considerados para demonstrativo gráfico apenas os 13 que tiveram representatividade maior que $1 \%$ do total das ocorrências registradas (Figura 5).

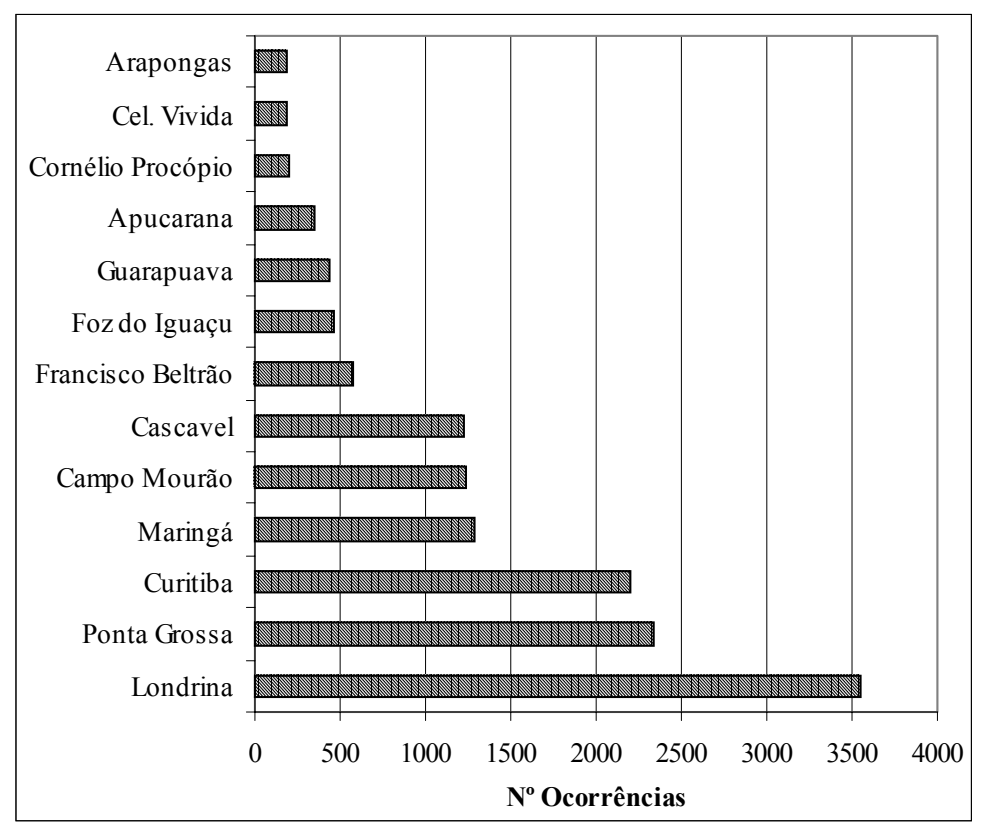

Figura 5. Distribuição das ocorrências de incêndios florestais por municípios do Paraná, no período de 1991 a 2001.

Figure 5. Distribution of the forest fire occurrences for counties of the Paraná, in the period of 1991 to 2001.

O município de Londrina registrou o maior número de incêndios no período analisado, ou seja 3.552 incêndios, correspondendo a $22,35 \%$ do total das ocorrências registradas, seguido de Ponta Grossa e Curitiba, respectivamente, com $2.339(14,72 \%)$ e 2.201 (13,85\%). Os três municípios juntos foram responsáveis por $50,92 \%$ do total das ocorrências registradas neste período. Das ocorrências registradas por município, apenas 13 municípios foram responsáveis por aproximadamente $90 \%$ do total. Observando-se na figura 5 os municípios de Curitiba, Ponta Grossa e Londrina, deve-se atentar para uma provável relação entre as ocorrências dos incêndios nessas cidades e o fato delas constituírem, respectivamente, segundo IBGE (2004) - censo 2000 -, a $1^{\circ}, 4^{\circ}$ e $2^{\circ}$ cidades mais populosas do estado.

\section{Principais tipos de vegetação atingida}

A figura 6 apresenta os registros de incêndios ocorridos nos diferentes tipos vegetacionais do estado do Paraná. Como se pode verificar, 3 dessas tipologias (mata, vegetação rasteira e capoeira) registraram $86,19 \%$ dos incêndios, sendo que a mata foi a vegetação mais comprometida no período 
(31,11\%), demonstrando que a tipologia que sofre a maior perda é justamente aquela de maior diversidade e significância ambiental. Soares (2001) registrou - em seu estudo comparativo sobre o perfil dos incêndios florestais no Brasil no período de 1983 a 1987 e no período de 1994 a 1997 - que, quando analisados em relação ao tipo de vegetação atingida no primeiro período, a maior ocorrência dos incêndios se deu em cerrados, campos e capoeiras; já no segundo período, a área queimada de florestas nativas foi significativamente maior, o que demonstra que a situação atual ainda é muito semelhante.

As áreas de vegetação rasteira vêm em seguida, com $30,32 \%$ da área comprometida. O principal reflexo desses incêndios é a degradação da qualidade do solo, considerando que essa operação ocorre todos os anos, causando prejuízos ainda à fauna e à flora.

$\mathrm{O}$ terceiro tipo de vegetação mais atingida pelo fogo foram as capoeiras, que são áreas em repouso pelo abandono da agricultura ou áreas em descanso para recuperação da produtividade e que ciclicamente retornarão à produção.

As áreas de reflorestamento e agricultura, respectivamente com 547 e 532 ocorrências, representaram menos que os valores obtidos para as ocorrências sem classificação específica, que corresponderam a 1.115 registros (equivalente a $7 \%$ do total do período analisado).

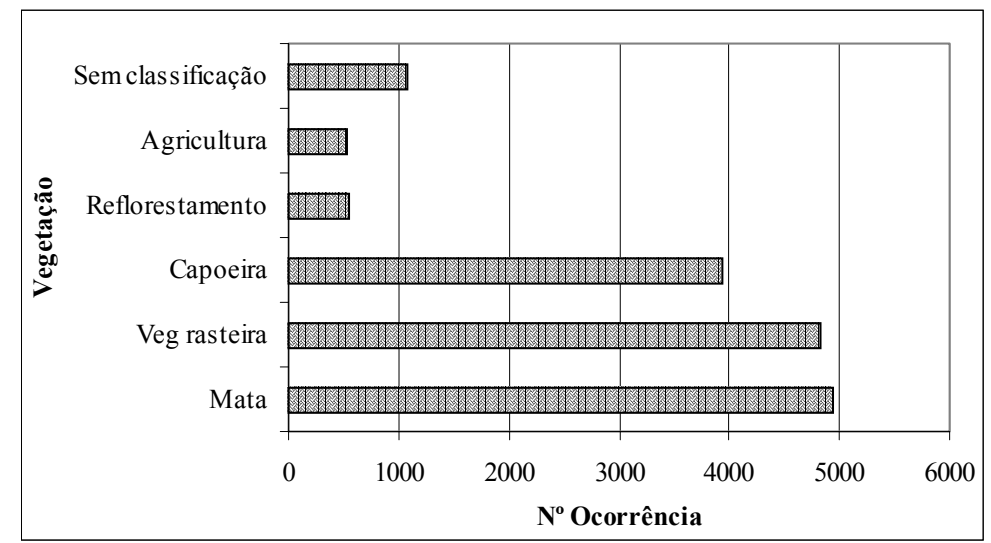

Figura 6. Vegetações atingidas nos incêndios registrados.

Figure 6. Vegetations reached in registered fires.

\section{Ocorrências por dias da semana}

$\mathrm{Na}$ figura 7, são apresentados os registros referentes às ocorrências de incêndios por dia da semana.

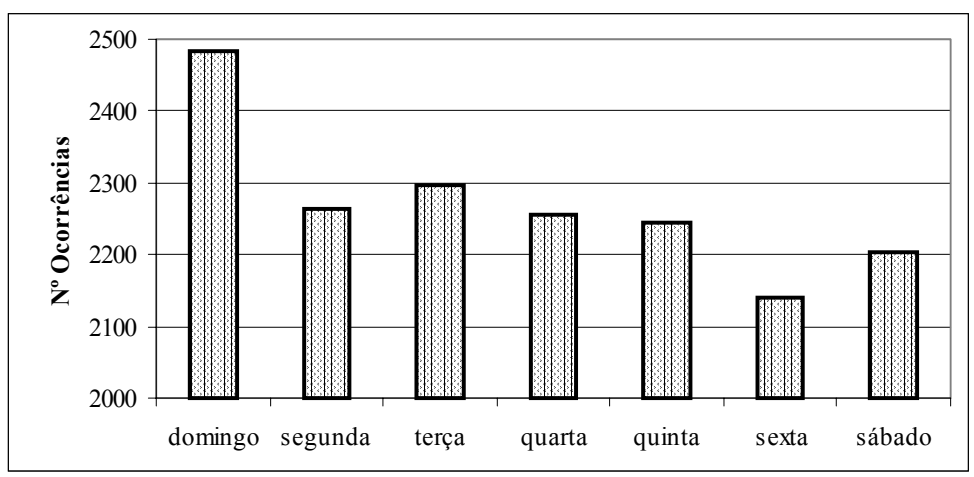

Figura 7. Número de ocorrências de incêndios por dia da semana registrados no período de 1991 a 2001. Figure 7. Number of the forest fire occurrences per day of week in the period of $1991-2001$. 
A análise das ocorrências dos incêndios nos dias da semana foi realizada objetivando verificar a existência de uma relação entre as ocorrências com as atividades desenvolvidas nos dias úteis ou nos finais de semana, a influência de atividade de lazer nos finais de semana, a relação com a fiscalização ambiental durante a semana, ou causas específicas que pudessem justificar ou evidenciar o número de ocorrências de incêndios para determinados dias da semana.

A tabela 2 apresenta os resultados da análise estatística dos dados coletados.

Tabela 2. Análise de variância do número de ocorrências de incêndios em relação aos dias da semana.

Table 2. Analysis of variance of the number of fire occurrences in relation to the days of the week.

\begin{tabular}{lccccc}
\hline Fonte de variação & SQ & GL & QM & F & P \\
\hline Tratamento & 6238,0 & 6 & 1039,67 & 0,15 & 0,9885 \\
Erro & 485836,0 & 70 & 6940,51 & & \\
\hline Total & 492074,0 & 76 & & & \\
\hline
\end{tabular}

A análise estatística demonstrou que não houve diferença significativa entre os dias da semana, sendo que apenas o domingo apresentou um pequeno aumento de incidência em relação aos demais dias, mesmo assim não diferindo estatisticamente dos demais. Na média, os incêndios se distribuíram homogeneamente entre todos os dias da semana. A hipótese de que incêndios estariam acontecendo em maior número nos finais de semana não foi confirmada.

\section{Causas dos incêndios}

Do universo total das 15.890 ocorrências, apenas 67 tiveram as causas registradas e, dentre estas, a maior incidência foi a de incêndios causados por fumantes, com $72 \%$ das ocorrências. O segundo maior registro foi o uso do fogo por crianças, com $18 \%$, de acordo com os resultados expressos na figura 8 . Fazse necessário mencionar que esses dados representam apenas $0,42 \%$ do número total de ocorrências de incêndios.

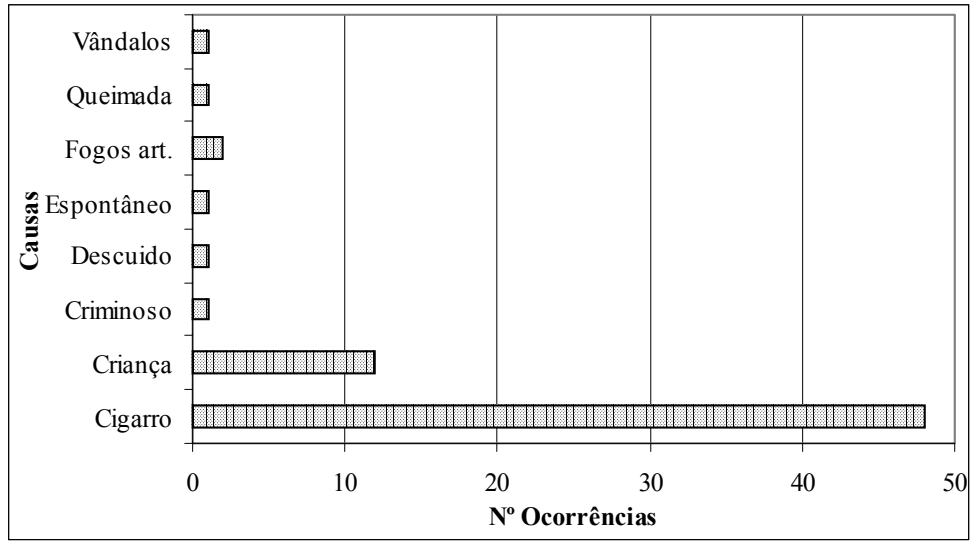

Figura 8. Causas registradas das ocorrências de incêndios.

Figure 8. Registered causes of the fire occurrences.

\section{CONCLUSÕES}

Os resultados obtidos através deste estudo permitiram concluir que:

- A forma de registro das ocorrências de incêndios florestais pelo Corpo de Bombeiros do Paraná não permite a obtenção das informações fundamentais para o planejamento da prevenção e do combate aos incêndios.

- Os anos de 1994, 1999 e 2000 apresentaram ocorrências de incêndios acima da média. 
- A maior incidência de incêndios florestais no Paraná aconteceu nos meses de julho, agosto e setembro.

- O maior número de ocorrências de incêndios registrados foi na região Norte do estado do Paraná.

- O município de Londrina apresentou o maior número de registros de incêndios atendidos pelo Corpo de Bombeiros.

- Os tipos de vegetação mais atingidos pelos incêndios no período foram as matas e vegetação rasteira característica de campos nativos.

\section{REFERÊNCIAS}

BATISTA, A. C.; SOARES, R. V. Manual de prevenção e combate a incêndios florestais. Curitiba: FUPEF, 1997. 50p.

IBGE, Área territorial oficial: consulta por unidade da Federação. Disponível em: $<$ http://www.ibge.gov.br> Acesso em: 22 out. 2004.

RODERJAN, C. V.; GALVÃO, F.; KUNIYOSHI, Y. S.; HATSCHBACH, G. G. As Unidades Fitogeográficas do Estado do Paraná. Ciência \& Ambiente, Universidade Federal de Santa Maria UFSM - Vol. 1, n 1, jul., 2002. p. 75-92.

SOARES, R. V. Incêndios florestais: controle e uso do fogo. Curitiba: Fupef, 1985.

SOARES, R. V. Perfil dos incêndios florestais no Brasil de 1979 a 1987. Brasil Florestal, Brasília, v. 18, n. 02, p. 94-121. 1989.

SOARES, R. V. Evolução do Perfil dos Incêndios Florestais no Brasil em dois períodos: 1983-1987 e 1994-1997. In: $2^{\circ}$ SIMPÓSIO LATINO AMERICANO E $6^{\circ}$ REUNIÃO TÉCNICA CONJUNTA IPEF/FUPEF/SIF DE CONTROLE DE INCÊNDIOS FLORESTAIS, 2001, Piracicaba. Anais... Piracicaba: 2001. 1 CD - ROM.

SOARES, R. V.; SANTOS, J. F. Perfil dos incêndios florestais no Brasil de 1994 a 1997. Revista Floresta, Curitiba, v.2, n.32, jul-dez. 2002.

VOSGERAU, J. L. Análise dos incêndios florestais registrados pelo corpo de bombeiros no estado do paraná no período de 1991 a 2001. Curitiba, 2005. 105 f. Dissertação (Mestrado em Engenharia Florestal) - Setor de Ciências Agrárias, Universidade Federal do Paraná. 